newly developing nations on a grand, concerted scale. In order to utilize science and scientists to facilitate understanding between nations, a United Nations weather and climate agency might be established to carry on research and ultimately to have authority over all weather and climate control undertakings. A United Nations university or system. of universities could be dedicated to the advancement of seience and the humanities. Other suggestions envisaged are the creation of an international translation and scientific information centre, and the establishment of adequate facilities to conduct research on technical problems of disarmament.

This study is the second of fifteen the Senate Relations Committee has authorized to examine United States foreign policy. It is designed to provide the Committee with background information, and the members are free to accept or reject the findings. The chairman, J. W. Fulbright, has announced that public hearings will be held later "to receive testimony from all interested parties in order to test the soundness of the findings and recommendations in all the studies undertaken".

\title{
NUTRITION IN EUROPE
}

\begin{abstract}
A SYMPOSIUM on "Education and Training in A Nutrition in Europe", arranged by the Food and Agriculture Organization of the United Nations and the World Health Organization through its European Regional Office, was held in Bad Homburg, West Germany, during December 2-11 1959. There were some sixty participants from twenty-two European countries, with Israel and Tunisia also represented. They belonged to a number of professional groups and included nutritionists, dietitians, physicians and public health officials, educationists, home economists and agronomists. The symposium was, in fact, designed to secure an inter-disciplinary approach.
\end{abstract}

The Food and Agriculture Organization and the World Health Organization are both concerned with nutrition; the former because its basic objective is to satisfy nutritional needs by making the necessary foods available, the latter because of the relation of nutrition to health. For many years they have collaborated in programmes and projects in this field, under the guidance of a joint expert committee. The meeting in Bad Homburg was one of a long series of joint undertakings.

The symposium began by attempting to define the nature and extent of problems of nutrition in Europe, a task facilitated by reports prepared boforehand by the participating countries. Generalization was naturally found to be difficult, in view of the wide differences in the countries represented. For northern, western and central Europe the picture is, on the whole, a favourable one. Under-nutrition and severe malnutrition are rare nowadays, the temporary food shortages of the War have been replaced by abundance, perhaps even by over-abundance. The child of to-day is more wisely fed than his predecessor of thirty or forty years ago and a number of fooddeficiency states and diseases once prevalent have been largely eliminated; it was noted, for example, that in certain countries teachers of medicine have great trouble in finding cases of rickets to demonstrate to medical students. However, even in the best-fed countries the goal of food for health has not been fully attained. For example, dental decay was mentioned as a widespread and distressing condition due to dietary errors, though unfortunately there is not yet general agreement on what these errors are. Again, over-nutrition and obesity are in a sense a form of malnutrition, and there was agreement both on their increasing prevalence and danger to health. The still unresolved problem of the relation between fat intake and the modern scourge of coronary disease was regarded as being somewhat outside the terms of reference of the symposium, but its importance was stressed by many members. It was pointed out that the increasing proportion of elderly people in the population presents dietary problems to which insufficient attention has as yet been given.

In other parts of Europe malnutrition still occurs in various groups of the population and in certain areas within the countries. The groups most affected are infants, young children and expectant and nursing mothers. It was reported that rickets is common in Poland and that pellagra is still found in a few pockets in eastern Europe.

More information on existing food consumption and state of nutrition is required, to help Governments in establishing national food policies which take account of nutritional needs, and to guide efforts to improve diet through education. With regard to the latter, however, mere average data on the quantities of various foods which people eat, and their celorie and nutrient value, are not enough. It is also necessary to understand why they eat what they do in the way they do. Food patterns are influenced by tradition and by a host of economic, social and psychological factors of which the 'educator' must be aware. The symposium entertained itself from time to time by exchanging anecdotes on the extraordinary ideas which people often have about food and diet.

After analysis of the situation had indicated that there is plenty of room for improvement and a wide need for public enlightenment, the symposium considered the adequacy or otherwise of the training in nutrition now given to various professional groups, dealing seriatim with nutritionists, dietitians, medical students, public health personnel, home economists, school teachers and agronomists and agricultural extension workers. The nature and content of training were discussed under each heading, after an introductory paper presented by a chosen member. Professional nutritionists (of whom there are all too few) need knowledge which is deep enough to enable them to provide leadership and guidance in their countries. Dietitians, defined as a class of worker concerned with organizing the feeding of groups and individuals, in particular the sick, also need extensive specialized training. With respect to most of the other groups, the symposium, aware of the need to avoid the further over-loading of curricula, did not favour adding nutrition to the curriculum as a separate subject ; it expressed preference for teaching it as part of other related subjects, provided the 
knowledge so imparted is inter-linked and becomes an 'integrated' whole. On the training in nutrition now given to medical students, the views of those present at the symposium were unfavourable; it was noted that while students receive some instruction in the science of nutrition in its clinical aspects, this is not given in an 'integrated' way and is rarely related to the everyday problems of family lifo.

Emphasis was placed on the contribution to popular education which can be made by the publie health nurse through her contacts with families in their homes. Home economists, a growing professional group in a number of European countries, can also influence families directly. As part of her work to improve family living conditions, the home economist is concerner with the planning of the family budget, the preparation of family meals, the domestic production, storage and preservation of food.

The training in nutrition of school teachers, so that they can teach its elements to their pupils, at an impressionable age, was discussed at some length. Ways of including nutrition in the teaching of subjects such as biology, health education and home economics were outlined, and it was agreed that it should not form a special and separate addition to school curricula. The need for simple and practical instruction was stressed, and attention was directed to the educational value of school meals.

Since good nutrition depends on the supply of enough of the right sort of food, it was appropriate for the symposium to consider the training in nutrition of agronomists and agricultural extension workers and their role in national nutrition programmes. Students in agricultural colleges learn much about the feeding of animals, but practically nothing about the feeding of human beings, which is after all the raison d'être of their profession.

Finally, the educational specialists present insisted that their colleagues should glance at modern educational techniques and modern ideas about the learning process, pointing out how these can be applied in the nutritional field. They were heard respectfully by a group in general more familiar with old-fashioned methods of instruction.

The symposium was aware that some of its con. clusions cannot be exactly applied to the different countries represented, but require adaptation to the circumstances and needs of each. In the animated discussions, however, a large measure of agreement was reached on major points. Throughout, the friendly atmosphere characteristic of international technical meetings prevailed. W. R. AYKROYD

\section{ELECTRON-PHONON INTERACTIONS}

\begin{abstract}
A CONFERENCE on Electron-Phonon Interactions in Solids was held at the Clarendion Laboratory, Oxford, during December 17-18. The Conference was held under auspices of the Physical Society and the delegates were welcomed by $\mathrm{Dr}$. K. A. G. Mendelssohn (Oxford) on behalf of the President of the Society. The subject-matter of the Conference was of a very specialized nature and the organizers had further restricted the field of discussion by excluding topics directly related to superconductivity. It was therefore most encouraging that more than one hundred delegates attended the Conference. Among these were visitors from the United States, Belgium, Canada, Holland, South Africa and Switzerland. These delegates were not all specialists in the subject-matter of the conference, but nevertheless the discussions which followed the formal papers were often lively and to the point.

The Conference devoted its attention to those aspects of electron-phonon interactions which are most closely concerned with the complicated processes usually classified as 'transport phenomena' in metals and semiconductors. Examples of such phenomena are the electrical and thermal conductivities or the thermo-electric effects. The classical kinetic theory of the 'free electron gas' gives a very simple and elegant explanation of most of these effects in a first approximation. However, this theory makes the very fundamental assumption that the electron gas is in thermal equilibrium at some particular temperature, but does not clearly describe a mechanism by which this equilibrium can be achieved. The approach to equilibrium is discussed in terms of 'collisions' which do not involve interactions. The difficulties of a more rigorous theoretical treatment were emphasized by Dr. G. V. Chester (Birmingham) and Dr. J. M. Ziman (Cambridge). Dr. Chester, in attempting a more rigorous approach using the 'adiabatic' approx-
\end{abstract}

imation, was rather surprised when experimentalists in his audience pressed him for some numerical orders of magnitude. Dr. Ziman reviewed the different methods at present used for estimating the electronphonon interaction. He suggested that the strength of this interaction in metals was related to the Fermi energy; but the discussion which followed Dr. Ziman's paper showed that some delegates thought that he may have over-simplified the problem by laying such stress upon one parameter-the closeness of approach of the Fermi-surface to the Brillouin-zone boundary.

Prof. F. J. Blatt (Michigan State University), Dr. D. K. C. Macdonald (National Research Council, Ottawa), and Dr. J. K. Drabble (General Electric Co.) presented papers dealing with experimental investigations of thermo-electric effects in metals and semiconductors. Prof. Blatt described an interesting serics of experiments which had been carried out using alloys of zinc, germanium, cadmium, indium, tin and antimony with copper. Of these alloys, 1 per cent zinc or germanium alloyed with copper gave a change in the thermo-electric power consistent with the expected phonon drag contribution estimated from pure copper. On the other hand, the addition of 1 per cent cadmium, indium, tin or antimony to copper reduced the phonon drag contribution almost to zero by virtue of phonon scattering arising from the solvent mass difference.

On the morning of the next day, Dr. A. B. Pippard (Cambridge) gave a simplified theoretical treatment of the anomalous absorption of ultrasonic waves by conduction electrons when the metal is situated in a magnetic field. Ultrasonic waves are essentially very long wave-length phonons, so that this technique provides in principle a direct approach to electronphonon interaction processes. Unfortunately, this anomalous absorption is difficult to measure and is 